\title{
POLLINATION ECOLOGY OF SABATIA CAMPESTRIS NUTT. (GENTIANACEAE)
}

\author{
Unpublished Report \\ University of Oklahoma Biological Station \\ Lake Texoma \\ 1972
}

\begin{abstract}
Constance E. Taylor
Professor Emeritus

Department of Biological Sciences

Southeastern Oklahoma State University

Durant, OK 74701-0609
\end{abstract}

Keywords: phenology, Sabatia campestris, autogamy, allogamy

\begin{abstract}
Flower timing studies in June and July (1972) on populations of Sabatia campestris Nutt. show this plant to be allogamous (out crossing) under natural field conditions. However, when environmental factors reduce populations of solitary bees or when flower populations are particularly extensive and dense, the uncollected pollen causes retention of anthers into the period of style opening and stigma presentation. Then autogamy (self-pollination) occurs. Pollinators observed were solitary bees in the genera Calliopsis, Dialictus, and infrequently Augochlorella. Pollen viability is generally excellent. A chromosomal count of $n=12$ indicated the presence of aneuploid races in this plant species. The lengthening of petals from anthesis to wilting and calyx from bud to fruit production indicates flower size cannot be used as a taxonomic character to separate species.
\end{abstract}

\section{INTRODUCTION}

Sabatia campestris Nutt. (Gentianaceae), prairie rose gentian, is a common prairie annual found from Illinois south through eastern Texas and east to Mississippi, with its greatest development in the prairie regions of the south central portion of the United States. The type specimen was collected from Oklahoma (Taylor and Taylor 1994) and its occurrence cited as "in the open prairies of Arkansas and Red River, common, flowering in June and July" (Nuttall 1836). The winged calyx that encloses the fruit is a unique species character. Perry (1971), studying cross fertilization between species, found $S$. campestris to be reproductively isolated from other species.

\section{DESCRIPTION OF THE FLOWER}

Flower timing studies in June and July (1972) on populations of S. campestris show this plant to be allogamous (out crossing) under natural field conditions. However, when environmental factors reduce populations of solitary bees or when flower populations are particularly extensive and dense, the uncollected pollen causes retention of anthers into the period of style opening and stigma presentation. Then autogamy (self-pollination) occurs.

The flowers are borne in a cymose inflorescence, the first flower terminal on a branch and subsequent flowers at the ends of opposite branches from below the first flower. The calyx is composed of five green 
sepals fused and winged at their lower edges, the lobes being 2-6 times longer than the calyx tube. The calyx continues to grow during flowering and during fruit maturation. The winged calyx tube lengthens to $8 \mathrm{~mm}$, and the calyx lobes grow to $25 \mathrm{~mm}$ long. The corolla is composed of five petals fused at the base, rose to pink or rarely white. Petal lobes, like the calyx lobes, grow during flowering, reaching $23 \mathrm{~mm}$ long and $13 \mathrm{~mm}$ wide. The base of each petal lobe fades to white and has a rectangular yellow mark about the size and shape of the anther. This mark increases in length and intensity of yellow color during flowering. There are five anthers and one pistil with two branches, first green, then turning yellow with maturity. Fruit capsules and seeds are numerous.

\section{METHODS}

The floral aspect of reproduction and pollinator behavior studies were done under field conditions during the height of blooming. Two plots located at the northeast edge of Durant, Bryan County, Oklahoma, approximately 1.21 and 4.86 hectares [3 and 12 acres] in size, were intensively observed. Two plots in Marshall County, Oklahoma, one adjacent to the University of Oklahoma Biological Station (U.O.B.S.) on Lake Texoma and another along a roadside $4.82 \mathrm{~km}$ [3 mi] north of Willis were also observed. During the height of blooming in early June, flowers were marked by crewel yarns in the bud stage and checked three times daily, at a minimum, and during one night to determine floral presentation and movement of flower parts. Climatic conditions were also noted. Studies of pollinator presence were made by halfhour monitoring over several days, and behavior of bees were observed and recorded with a $35 \mathrm{~mm}$ single lens reflex camera. Autogamy (self-pollination) was confirmed by the use of pollinator exclusion bags. No seed set was obtained when styles were excised.

\section{RESULTS}

\section{Observations}

The following description of floral presentation is for a sunny summer day in the presence of pollinators - solitary bees. S. campestris is protandric (the anthers functioning first) with the opening bud displaying straight anthers; the green pistil with tightly twisted styles lies in a horizontal position when the flower is fully open. By 8:30 a.m. (CDST), the anthers will have recurved at the tip, splitting open to release pollen from the anther chamber (Figure 1). The timing of anther dehiscence is delayed by rain and cloudy weather, recurvation of anther tips and pollen presentation being delayed until as late as 11:30 a.m. under these conditions. The flower closes in the late evening, so no opening to floral parts is apparent. Closure is not as tight as in the bud. The first night is the only night full closing occurs.

On the second day, the anthers gradually curl further back and eventually tilt into a horizontal position. Anther presentation of pollen is usually for two days but may be extended for a third day. On the morning of the third day, the anthers fall to the center of the bowl shaped flower. Flowers presenting anthers for a third afternoon usually have anthers fall off the filaments in the evening. Anther presentation is greatly modified by pollinator absence, being considerably prolonged for another one or two days.

Presentation of the stigmatic surface typically begins with the falling of the anthers. While still in a horizontal position, the stigmatic surfaces begin to turn yellow. Staining with lactophenol aniline blue indicated receptivity is correlated with the appearance of the yellow color. The twined style branches begin untwisting gradually. Over 24 hours is required for the style to 
become erect and the stigmatic branches to completely untwist. Stigmatic presentation is from the third day after opening (Figure 2) until the flower wilts on the $6^{\text {th }}$ or $7^{\text {th }}$ day. Some blossoms showed stigmatic wilt prior to petal wilt. The sepals are retained until the fruit dehisces some months later.

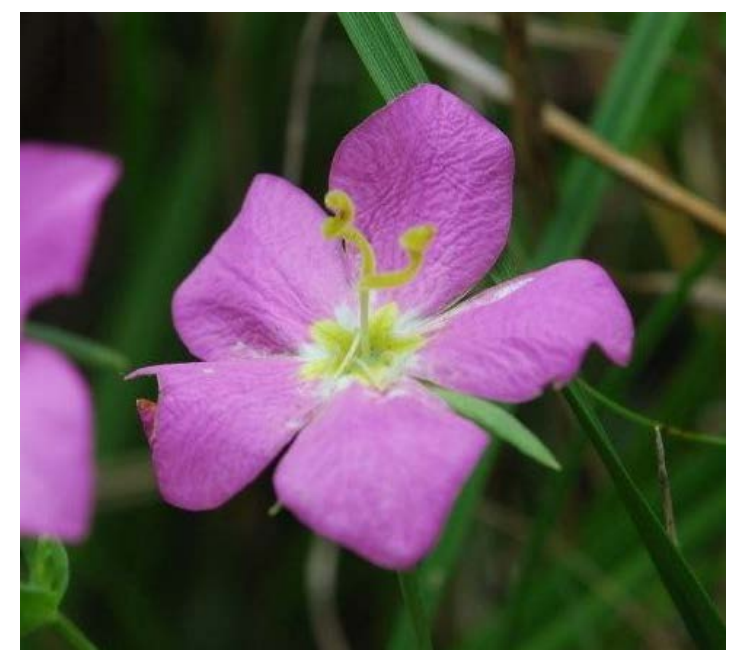

Figure 1 Late day 2 showing curled dehiscence of anthers and unreceptive pistil with tightly twisted styles

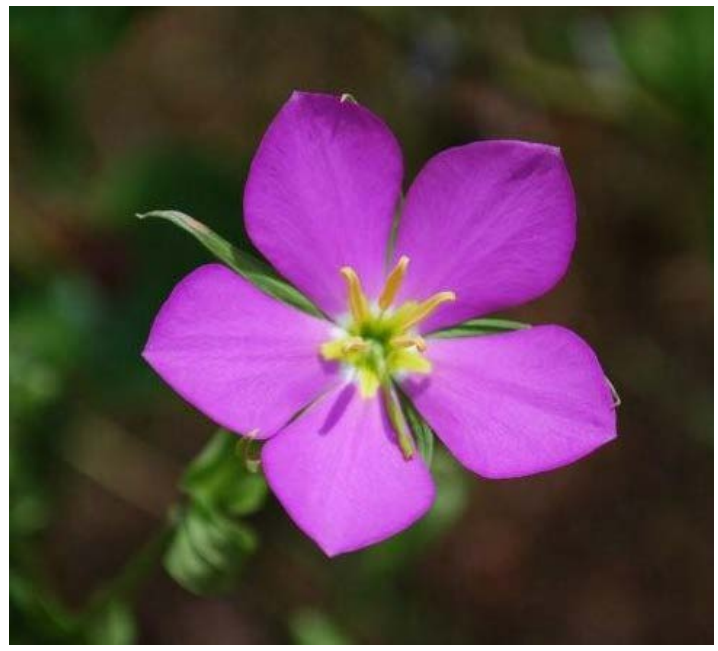

Figure 2 Day 4 or 5 showing erect style with receptive untwisted style branches, no anthers, and mimic anther lines at base of petals

\section{Pollination}

Pollinators visiting S. campestris were solitary bees in the genera Calliopsis
(Andrenidae), Dialictus (Halictidae), and Augochlorella (Halictidae). All species of solitary bees were shorter than the anther length. Visits were for pollen collection. Day and time of visitation and plot visited are summarized in Table 1. The flowers produced no nectar and seemed to hold little attraction for most other insects. Occasional visits by various crab spiders and insects from leaf hoppers to butterflies were noted, but they were scattered and infrequent. In the Durant plots, the size of the three principal pollinators diminished. The largest-sized species visited before June 10; the middle-sized species visited in midJune; and toward the last few days of June and first two weeks of July, the smallest bee species was the pollinator.

The ecological interactions of bee and flower are pronounced. When flowers are open in the absence of pollinators, the anthers remain in an upright position for extended periods of time, and the total length of blooming is increased. Flowers in paper pollinator exclusion bags and screen wire cages had, by the $5^{\text {th }}$ and $6^{\text {th }}$ days, accumulated piles of pollen heaped on the anther and scattered in the bowl of the blossom. The presence of this accumulation of dehisced pollen excluded wind pollination as an effective pollination agent. The presence of anthers remaining in an upright position delayed stigma presentation for several days, as late as six or seven days after opening. Blooming time per flower was dramatically extended, one flower remaining unwilted for 14 days with the stigma still yellow and upright.

Collection of pollen was done in the same manner by all species of bees. After landing on the petal platform, they climbed up the anther, usually from the interior portion of the blossom. With the use of mouth parts, the pollen was collected and transferred by the front legs to the corbicula. After collecting for some minutes, the bee then packed the pollen into 
Table 1 Times of bee visitation observed for plots

\begin{tabular}{|c|c|c|c|}
\hline POLLINATOR & \multicolumn{2}{|c|}{ VISITATION } & LOCATION \\
\hline & DATE (1972) & TIME (CDST) & \\
\hline Calliopsis sp. & before June 10 & $12: 30-3: 30$ & Durant \\
\hline Dialictus sp. (black) & June & early morning & U.O.B.S. \\
\hline Dialictus sp. (black) & late June & all afternoon & Durant \\
\hline $\begin{array}{c}\text { Dialictus } \text { sp. } \\
\text { (metallic rust) }\end{array}$ & late June-early July & all afternoon & Durant \\
\hline Augochlorella sp. & mid-June & noon & $\begin{array}{c}\text { U.O.B.S. and } \\
\text { N. of Willis }\end{array}$ \\
\hline
\end{tabular}

a firmer mass and was observed flying off for about one foot from the petal and then returning to the same blossom for further pollen. Anthers were usually worked in a counter-clockwise manner, taken one after another until pollen from all five were collected. A blossom was worked sometimes two or three more times around. The longest timed collection of pollen from one flower by one bee was seven minutes.

Bees seemed to be unable to discriminate between flowers presenting anthers and those presenting stigmatic surfaces until landing on the flower. A bee quickly realized the absence of collectable pollen and would fly immediately to another flower. No bee was observed on a flower without anthers for more than $15 \mathrm{~s}$, unless the petal platform was used when packing pollen. As the bee climbed on the style branches in the same manner it did the stamens, the pollen of the corbicula brushed the stigmatic surface causing pollination. Quadrat sampling confirmed the hypotheses that pollen reward for bee visitation occurred in less than 40 percent of the blossoms open at any one time. Later in the bloom season, sampling showed flowers presenting pollen fell to 27 percent of the total open blossoms.

Pollen viability counts were made on material stained with either lactophenol analine blue or Snow's stain. Pollen viability was generally less than $1 \%$ non-viable pollen. Highest count of non-viable pollen was $41.7 \%$. Lewis et al (1962) and Perry (1971) reported chromosome numbers of $n=13$. Collections of buds were made at three different times from the 1.21 ha [3 acre] Durant plot. All three counts were $\mathrm{n}=12$. Chromosomal numbers for the genus as reported by Perry (1971) are $n=13,14$, $16,17,18,19,32$, and 38 .

\section{DISCUSSION}

Perry (1971) reports the sequence of events in anthesis of Sabatia flowers for all species. His data for $S$. campestris are bud (day 1), petals expanding and anthers recurving (day 2), anthers dehiscent (day 3), pollen shed (days 7-8), and stigma uncoiling and receptivity (days 7-8). I assume floral timing is based on greenhouse plants, as he states his pollination and fruit set studies are done under these conditions. His data for floral timing is the same as the data I recorded under pollinator exclusion bags, indicating that this species is generally crosspollinated. However, in the event of environmental influences which would hinder pollinator visits, the plants will set seed by self-pollination. 
In the smaller plots, pollen collection was efficient throughout the blooming season. The 4.86 ha [12 acre] plot, densely populated by $S$. campestris, always had occasional blossoms from which pollen had not been collected. During observations, over a dozen flowers were observed with direct mechanical self-fertilization occurring by direct contact of the stigma surface with the anther. The only flowers not setting fruit were those which wilted during dry periods. All flowers in pollinator exclusion bags set fruit. In young plants with few blossoms, synchronization of flowers on the same plant was observed, all blossoms either presenting anthers or all presenting stigmas, but not presenting both on the same plant. Older plants with eight or more flowers usually lost this synchronization.

Each $S$. campestris blossom has a small eye or star located at the center of the flower. Each petal has a single yellow or green-yellow line notched at the apex, presented against a white background. The yellow line and white area enlarge and lines assume a bright yellow - at least to the human eye-as the stigmatic surfaces are presented. After anther shed, the yellow streaks and large yellow divergent style branches together provide a facsimile to the yellow flicker pattern of the presented anthers. The evolution of this pattern is often considered to be due to long and close bee pollinator association, with patterns on blossoms considered as nectar guides. This does not seem to be the case in $S$. campestris. The petals are pink, a color not generally associated with bee flowers. Various shadings were common in all plots, ranging from white, light pink, pink, to dark pink. Ultraviolet reflection did not occur on blossoms tested.

The floral whorls, both calyx and corolla, grow after anthesis. This extremely unusual growth pattern is responsible for the enlargement of the eye. The largest flower on any plant will be that blossom which has been open longest. Wilber (1955) noted that on some plants the central blossom was largest. Neither Wilbur (1955) nor Perry (1971) mention the continued growth of the blossom while in bloom. The calyx also continues growth after the petals wither. Length and width of the calyx and corolla have been used as taxonomic character to separate species. The phenomenon of continued growth also occurs in at least two other species. Examination of fresh flowers of a population of $S$. angularis (L.) Pursh, collected in June on the east side of the Glover River at Arkansas Crossing, McCurtain County, Oklahoma, showed the same size differentiation. The lengthening of petals from anthesis to wilting and calyx from bud to fruit production indicates flower size cannot be used as a taxonomic character to separate species. Differences of individual blossoms on a single plant varied from 5 to $9 \mathrm{~mm}$ as measured from petal tip to petal tip tangent to the fruit. Likewise, examination of specimens collected from a population of $S$. arenicola Green, collected in April from a littoral area behind the dunes $12.87 \mathrm{~km}$ [8 mi] west of Sabine Pass, Texas, showed size differences. Measurement of the petal lobes showed they increased between 2 and $3 \mathrm{~mm}$ from early blooming flowers to old blossoms beginning to wilt. Flowers in fruit had longer calyx lobes than those in flower. Continued growth of blossoms is suspected for other species from descriptions and discussions in the monograph (1955) of the genus.

\section{ACKNOWLEDGEMENTS}

Thanks are due to Dr. J. R. Estes for direction in cytological work and to Dr. R. W. Thorp who identified the bees. Special recognition to Dick Carson, Stone Post Creations (rosecarson@juno.com), for the photographs of Sabatia campestris. 


\section{LITERATURE CITED}

Lewis, W.H., H.L. Stripling, and R.G. Ross. 1962. Chromosome numbers for some angiosperms of the southern United States and Mexico. Rhodora 64:147-161. Nuttall, Thomas. 1836. Transactions of the Philadelphia Society. n.s. 5:197-198.

Perry, J.D. 1971. Biosystematic studies in the North American genus Sabatia (Gentianaceae). Rhodora 73:309-369.
Taylor, R. John and Constance E.S. Taylor. 1994. An Annotated List of the Ferns, Fern Allies, Gymnosperms and Flowering Plants of Oklahoma. $3^{\text {rd }}$ edition. Self-published. Wilber, R.L. 1955. A revision of the North American genus Sabatia (Gentianaceae). Rhodora 57:2-104. 